\title{
Impact of Drill and Blast Excavation on Repository Performance Confirmation
}

\author{
Roger Keller*, Nick Francis+, Jim Houseworth++, and Norman Kramer* \\ +Sandia National Laboratories, ++ Duke Engineering \\ * Mining Engineer, Washington Group International \\ For Presentation at the \\ 2001 International High-Level Radioactive Waste Management Conference \\ April 29- May 3, Las Vegas, Nevada
}

\begin{abstract}
There has been considerable work accomplished internationally examining the effects of drill and blast excavation on rock masses surrounding emplacement openings of proposed nuclear waste repositories. However, there has been limited discussion tying the previous work to performance confirmation models such as those proposed for Yucca Mountain, Nevada. This paper addresses a possible approach to joining the available information on drill and blast excavation and performance confirmation.

The method for coupling rock damage data from drill and blast models to performance assessment models for fracture flow requires a correlation representing the functional relationship between the peak particle velocity (PPV) vibration levels and the potential properties that govern water flow rates in the host rock. Fracture aperture and frequency are the rock properties which may be most influenced by drill and blast induced vibration. If it can be shown (using an appropriate blasting model simulation) that the effect of blasting is far removed from the waste package in an emplacement drift, then disturbance to the host rock induced in the process of drill and blast excavation may be reasonably ignored in performance assessment calculations.
\end{abstract}

This paper proposes that the CANMET (Canada Center for Mineral and Energy Technology) Criterion, based on properties that determine rock strength, may be used to define a minimum PPV. This PPV can be used to delineate the extent of blast induced damage. Initial applications have demonstrated that blasting models can successfully be coupled with this criterion to predict blast damage surrounding underground openings. The Exploratory Studies Facility at Yucca Mountain has used a blasting model to generate meaningful estimates of near-field vibration levels and damage envelopes correlating to data collected from pre-existing studies conducted. Further work is underway to expand this application over a statistical distribution of geologic parameters, encompassing all the rock types that will be encountered for the proposed repository site at Yucca Mountain.

This paper suggests that, based on predicted and verified vibration levels from blasting a distance equal to four standard deviations is unlikely to affect properties that govern water flow in the host rock. The authors propose this predicted distance and verification of vibration levels may be applied to the excavation of repository subsurface openings that may be most efficiently excavated by drill and blast methods with a reasonable assurance of safety. 